"An analytical study on customer perception of store environment and its effect on brand loyalty through joy of shopping (a case study: LG home appliance store)"

$\begin{array}{ll} & \text { Mehran Ghaedi Heidari } \\ \text { AUTHORS } & \text { Hamed Alibeigi } \\ & \text { Ali Aghaeifar }\end{array}$

Mehran Ghaedi Heidari, Hamed Alibeigi and Ali Aghaeifar (2016). An analytical

ARTICLE INFO study on customer perception of store environment and its effect on brand loyalty through joy of shopping (a case study: LG home appliance store). Problems and Perspectives in Management, 14(3-si), 380-387. doi:10.21511/ppm.14(3si). 2016.11

DOI http://dx.doi.org/10.21511/ppm.14(3-si).2016.11

RELEASED ON Thursday, 15 September 2016

JOURNAL

"Problems and Perspectives in Management"

FOUNDER

LLC "Consulting Publishing Company "Business Perspectives"

NUMBER OF REFERENCES

0
NUMBER OF FIGURES

0

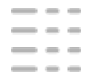

NUMBER OF TABLES

0

(C) The author(s) 2023. This publication is an open access article. 
Mehran Ghaedi Heidari (Iran), Hamed Alibeigi (Iran), Ali Aghaeifar (Iran)

\title{
An analytical study on customer perception of store environment and its effect on brand loyalty through joy of shopping (a case study: LG home appliance store)
}

\begin{abstract}
This study attempted to analyze customer perception of environment in an LG store and its effect on brand loyalty through joy of shopping. This was an applied, descriptive-correlational research involving a survey. The population included all buyers of LG home appliances at stores based in Isfahan. Moreover, simple random sampling was employed. Validity of the questionnaire was calculated through content validity and confirmatory factor analysis, while its reliability was confirmed through Cronbach's alpha at 0.88 . Of the 250 questionnaires distributed among customers, 231 were completed and returned for analysis. Data were analyzed through SPSS and AMOS based on descriptive statistics (frequency, percentage, mean and standard deviation) and inferential statistics (confirmatory factor analysis, path analysis with significance level). According to the results, the main hypothesis was proved, suggesting there is a significant relationship between store environments through joy of shopping on customer loyalty. Furthermore, the subhypotheses were proved, suggesting environment, human interaction and in-store design affect joy of shopping and joy shopping, in turn, affects customer loyalty. In comparison of the research hypotheses, environment left the greatest impact on joy of shopping, followed by human interaction and store interior design are effective in joy of shopping. Finally, there are three components of environment, human interaction and design indirectly leaving a significant effect on brand loyalty through joy of shopping as a mediating variable.
\end{abstract}

Keywords: joy of shopping, store environment, consumer behavior, brand loyalty.

JEL Classification: D11, D12, M31.

\section{Introduction}

One of the undeniable facts of competitive business environment today is the effect of store environment on customer behavior involving attraction, higher purchase rate and loyalty. Store environment refers to all physical and non-physical elements inside a store that can be controlled to enhance the efficiency of behavior of customers and employees (Slatten et al., 2009).

Tendency of different stores to provide a businessfriendly, pleasant and attractive environment for customers highlights the fact that internal environment of stores is effective in customer behavior. Given the growingly competitive space and offering so similar products within one price range, it is the interior design practices of stores serving as a powerful tool to create a more appealing space, thereby to differentiate from competitors and attract more customer. Without a doubt, customers who visit a shopping place for its great reputation and credibility stress the fact that those stores must have invested huge amount of time and money (Leigh Coley, 2002).

Building a brand surpasses the marketing and advertising realm, entailing an economic, as well as a social structure. One of the well-recognized

(c) Mehran Ghaedi Heidari, Hamed Alibeigi, Ali Aghaeifar, 2016.

Mehran Ghaedi Heidari, M.A. Student, Faculty of Executive Management, Islamic Azad University, Khorasgan Branch, Iran.

Hamed Alibeigi, M.A. student, Faculty of Executive Management, Islamic Azad University, Khorasgan Branch, Iran.

Ali Aghaeifar, Ph.D., Faculty of Executive Management, Islamic Azad University, Semirom Branch, Iran. essential concepts in marketing is brand loyalty. It plays an important role in creating long-term benefits for the company, because loyal customers do not need any extensive promotional efforts. Quite willingly, they will pay more money to gain the advantages and quality of their favorite brand. In fact, brand loyalty is the core of marketing in theory and practice in building a sustainable competitive advantage (Meller and Hansan, 2006).

\section{Literature review}

Loyalty to store is typically defined as follows: behavioral response informed (rather than accidental) repeated visits to a particular store among multiple other stores, due to a psychological decision leading to a commitment to the store. In other words, loyalty to the store refers to something more than merely repeated visits, rather covering a level of attachment to the store (Bridson et al., 2007). Martinio first raised the discussion of store image, describing it as follows. Store image is a concept crystalized in the mind of the customer, which partly concerns functional features and partly the psychological features of the store. Linguist argued that there is a difference between the functional and psychological features of a store. Accordingly, store image is the general impression of customers about the store, typically involving two perceptual and emotional components. The former entails customers' perception of functional quality in the store. The latter refers to how customers feel about the store (Haiyan and Cynthia, 2006). Diversity of consumer behaviors is rooted in various factors contributing to 
purchase intent. Employment of consumer behavior knowledge for developing marketing strategy is somewhat an art (Samadi et al., 2010).

It is crucial to gain a good insight about consumers and purchase process. The decision made by consumers inside a store is affected by many factors, which can be either internal or external. The latter may cover cultural, economic, political, and legal factors, as well as those within the corporate scope of power (such as in-store elements). On the other hand, internal factors involve motivation, perception, personality, and other such intrinsic factors emanating from individual qualities. Due to their intensely competitive market of their products, companies can no longer disregard tastes, interests, wishes and needs of their customers. Hence, the key mission of organizations for attaining their goals is to focus on the different needs of consumers and meet their demands accurately and timely (Fernie et al., 2001).

Hedonic shopping involves a series of unplanned purchases characterized by two factors. Firstly, hedonic shopping refers to purchases subject to impulsiveness rather than an intent of shopping. Basically, hedonistic shoppers seldom think about their actions and are attracted to products rather emotionally, seeking instant gratification of their desires. This type of consumers often pay little attention to the potentially adverse consequences of their actions (Adelaar et al., 2003). Every store is expected to make an effort to enhance customer loyalty. Moreover, many scholars have concluded that store image is one of the critical components contributing to customers' loyalty to the store. In order to achieve customer loyalty to the store, their mental picture of the store should be meticulously considered. One of the goals of marketing is to raise corporate profits by increasing frequent purchases along with loyalty to products/services. It is expected that high loyalty to products/services will bring about several benefits such as frequent purchases, highquantity purchases, lower costs and optimum mouthto-mouth advertising (Jin et al., 2005).

Dick and Bessou believed that loyalty is an outcome of positive attitude toward the store and repeat purchase behavior. Constant appropriate loyalty will be realized only when the customers show repeat purchase behavior, frequently visiting the same store. Moreover, they will take a positive attitude toward the store and prefer it over others. Since it is easier to measure the behavioral aspect of loyalty, researchers have been mainly focusing on the behavioral aspect of loyalty measuring the level of loyalty (Demoulina and Zidda, 2008). Depending on its various features, the entire customer perception of the store constitute store image (Yasamin, 2010).
Moreover, Copp Ferrer pointed out a combination of functional and symbolic elements by considering the physical aspect, personality, culture, relationship, intellect and interests of customers. Furthermore, he emphasized how customers decode these issues.

The cross-influence of tangible and intangible elements and overall impression of customers based on previous knowledge and experience have been in most cases recognized as the definition of store image (Burt and Encinas, 2000). Given the fact discussed so far, any business activity requires loyal customers so as to achieve success and stability. In this respect, customer mental image is one of the key contributing factors to mental image. This study is unique, because there are no similar efforts simultaneously examining the relationship between customer perception of store environment, brand loyalty and joy of shopping. In practical terms, this study can be important for every small, medium or large store in identification and understanding of consumer purchase behavior and their loyalty mechanism.

Accordingly, customer perception of store environment is effective in customer satisfaction and loyalty to store brand through joy of shopping as an intermediating variable. In fact, this study attempted to find an answer to the question how customer perception of store environment affects brand loyalty given the intermediating role played by joy of shopping. On that basis, the major objective of this study was to evaluate the effect of customer perception of store environment on brand loyalty through joy of shopping as an intermediating variable.

Hiu Jong Chang et al. (2011) studied the application of SOR model in retail sale environments focusing on the role of hedonic intent in impulse purchase behavior. The results were as follows:

1. Environmental characteristics of the store are effective in positive emotional response of consumers.

2. Positive emotional response is effective in impulse purchase behavior.

3. Hedonic intent of consumers intermediates environmental characteristics and positive emotional response.

In their study involving store environment and impulse purchase, Tendai and Crispen (2009) argued that instore displays, advertising, employee behavior, and prices were most critical among 9 factors identified in impulse purchase of coupons. Moreover, $62.5 \%$ of impulse purchases were under 30 years old. In-store environment is effective in impulse purchase. Among the poor, there are more important factors with economic nature, such as price and coupon. The atmosphere inside the store (such as music and aroma) help to stay longer in the store. 
In their study on consumer impulse purchase and store indoor stimuli in Chinese supermarkets, Ju and Wong (2008) examined the effects of posters on point-of-purchase (POP) through two aspects. Firstly, the posters left a promotional informative effect based on lower price and discount. Secondly, the practical atmosphere effect including enjoyment, modern quality and attractiveness). Store indoor posters should not merely display discount and lower prices, but rather be applied as environmental stimuli. They can provide a strategy for enhancing impulse purchase. In this regard, family incomes plays a key role in their impulse purchase.

In a study focusing on impulse purchase, personality traits, in-store atmosphere and their relationships, Nakheel Jalan (2006) divided the contributing to impulse purchase into internal and external factors. The former was characterized by subcategories of sensation and personality characteristics, while the latter involved demographic, social, economic, marketers, etc. This study considered items of environment, design, society and others for in-store factors. It was concluded that in-store factors have, similar to external factors, a significant effect on impulse purchase.

In a study on the effect of music clip on in-store shopping (duration of customer stay inside the store), Hosseini et al. (2013) stated that competition today is not limited to manufacturing enterprises, but rather affects their suppliers and particularly large retail sellers. Due to the Iranian cultural infrastructure, these large retail sellers have to face a huge crowd of small retailers who need to attract more customers and enhance purchase rate through employment of modern marketing techniques so as to expand the duration of customer stay inside the store and subsequently increase the chances of purchase. One of such methods is to play music clips inside the store. In that study, effort was made to examine how music clips can affect the duration of customer stay within the store environment and enhance purchase rate. The population covered the customers of large stores in Rasht. The results were evaluated through path analysis indicating that music clips left an impact on purchase rate by extending the duration of customer stay in the store. One the other hand, there were significant difference between customers depending on ecological characteristics.

Aghazadeh, Gholipour and Bakhshizadeh (2013) studied the effect of brand personality on repurchase intent through perceived value and brand loyalty (a case study of Saman life insurance policyholders). They argued that brand loyalty played an important role in success of businesses, improvement of perceived value, strong customer relationship, as well as their loyalty and repurchase intention. This research examined the impact of brand personality of Saman Insurance Co. and its dimensions (based on brand personality model by Jennifer Aaker) includes sincerity, excitement, competence, sophistication and ruggedness on perceived value and brand loyalty (consequences of brand personality) and their impact on repurchase intent of 267 life policyholders at Saman Insurance based in Tehran. The results indicated there was a significant and positive correlation between all variables. The findings of regression analysis demonstrated that brand personality of Saman Insurance had a significant effect on perceived value and brand loyalty of life policyholders. Moreover, the perceived value and brand loyalty affect the consumer repurchase intention. The results suggested that sincerity, competence and ruggedness affected the perceived value while sincerity, excitement and competence affected brand loyalty. In this regard, competence had the largest impact on perceived value and brand loyalty of life policyholders.

Store space refers to all physical and non-physical elements of a store controlled to achieve efficient behavior in customers and employees (Leith Kelly, 2002).

Joy of shopping is a positive and happy feeling arising from customer satisfaction (Earth et al., 2010).

Brand loyalty involves a positive attitude toward a particular product, rooted in frequent use mainly due to psychological mechanisms. In other words, repeat purchase is not merely a voluntary action, but is rather an outcome of psychological, emotional and normative factors (Meller, 2006).

\section{Main hypothesis}

Customer's perception of store environment has a significant impact on brand loyalty through joy of shopping.

\section{Sub-hypotheses}

1. Environment has a significant impact on joy of shopping.

2. Human interaction has a significant impact on joy of shopping.

3. Design has a significant impact on joy of shopping.

4. Joy of shopping has a significant impact on customer loyalty. 


\section{Conceptual model}

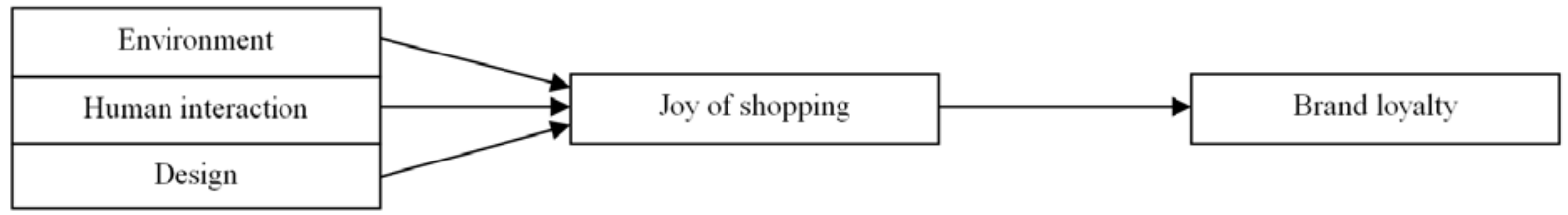

Fig. 1. Research conceptual model

Source: Slatten et al. (2009).

\section{Methodology}

Given that the researcher in this study intended to analyze the impact of customer perception of store environment on brand loyalty through joy of shopping based on customer reviews about LG home appliances store, it can be regarded an applied, descriptive-correlational survey. The population involved all the customers visiting an LG home appliances store in Isfahan. Since the population was unlimited, 231 individuals were selected as sample through Cochran's formula. The questionnaire were handed out by simple random procedure. In this research, store environment, three components (environment, human interaction and design), and other variables including joy of shopping and brand loyalty were assessed through Slatten and Mehmetoglu (2002) standard questionnaire. The internal structure of the questionnaire was analyzed and its validity was calculated through formal validity, as well as several university elite and supervisors based on the results of confirmatory factor analysis, where the standard factor loadings were calculated for each item. Since the factor loading values for all items were greater than 0.5 , there was an adequate validity. Moreover, the reliability was confirmed through Cronbach's alpha at 0.88 . The dependent variables were assessed through descriptive statistics including mean, standard deviation, median, etc. The main variables and inferential statistics were tested through structural equations and path analysis given the need to examine the effect of independent variables on the dependent variables.

\section{Findings}

Data were analyzed through SPSS and AMOS.

\subsection{Descriptive measures of data.}

Table 1. Descriptive results of questionnaire components

\begin{tabular}{|l|c|c|c|c|c|c|}
\hline \multicolumn{1}{|c|}{ Component } & Mean & Standard deviation & Variance & Median & Minimum & Maximum \\
\hline Environment & 3.05 & 0.372 & 0.139 & 3 & 1 & 5 \\
\hline Human interaction & 2.94 & .331 & 0.110 & 3 & 1 & 5 \\
\hline Design & 3.01 & 0.426 & 0.182 & 3 & 1 & 5 \\
\hline Joy of shopping & 2.96 & 0.451 & 0.204 & 3 & 1 & 5 \\
\hline Brand loyalty & 3.15 & 0.396 & 0.168 & 3 & 1 & 5 \\
\hline
\end{tabular}

6.2. Confirmatory factor analysis. In the structural equations modeling, the consistency of data and conceptual model is evaluated whether there is goodness of fit. Moreover, the significance level of each relationship is tested. The key indicators included Chi-square $\left(X^{2}\right)$, goodness of fit index (GFI) and adjusted goodness of fit index (AGFI). In this procedure, any model with desirable goodness of fit will have $X^{2} / d f$ smaller than 3. Moreover, there will be goodness of fit when GFI and AGFI values are closer to one.

This section provides the results of confirmatory factor analysis on each variable separately through AMOS. It should be noted that the number of latent variables was curtailed so as to obtain factor loading of greater than 0.5 . In evaluation of each model, the major question is whether or not these models are appropriate. This can be answered by examining $X^{2}$ and other criteria of goodness of fit. In fact, an appropriate model will meet the following optimum conditions. Lower value of Chi-square test the better, since it reflects the difference between data and model.

The lower the value of RMSEA test the better, since it reflects the mean square of model errors. Generally, the confirmatory factor analysis develops a model where the empirical data are assumed to have been described or calculated based on several parameters. Such model is based on previous information about data structure derived from a theory, hypothesis or knowledge drawing on previous studies. 
Table 2. Goodness of fit indices

\begin{tabular}{|c|l|l|c|}
\hline No. & \multicolumn{1}{|c|}{ Test } & \multicolumn{1}{|c|}{ Main index } & When is there model goodness of fit? \\
\hline 1 & RMSEA & Mean square errors & $>0.1$ \\
\hline 2 & $X^{2}$ & Difference between frequency observed and expected & $\leq 0.9$ \\
\hline 3 & CFI & Comparative fit index & $\leq 0.9$ \\
\hline 4 & GFI & Evaluation of the relative variance and covariance & $\leq 0.9$ \\
\hline 5 & AGFI & Mean of squares instead of sum of squares in the above model & $\leq 0.5$ \\
\hline 6 & RMR & Residual variance and covariance & \\
\hline
\end{tabular}

6.3. Second-order confirmatory factor analysis for store environment measurement model. The results in Figure 2 for store environment measurement model suggested the factor loadings were adequate (greater than 0.5$)$.

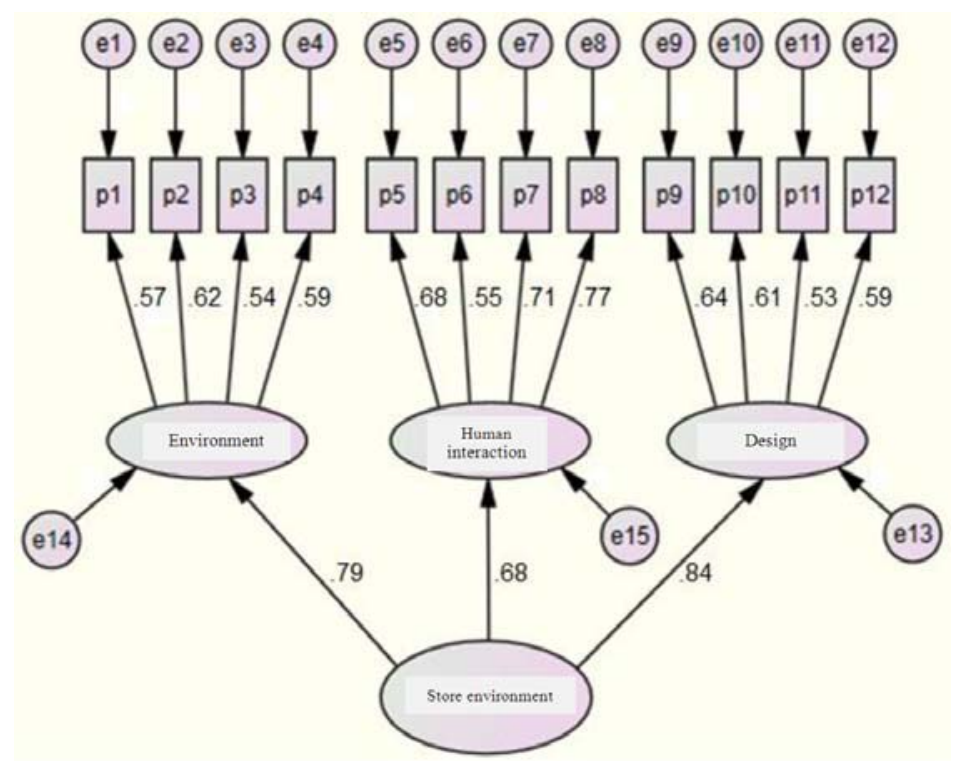

Fig. 2. Second-order confirmatory factor analysis for store environment

According to figures displayed in Table 3, GFI and AGFI refer to relative variance and lower Chi-square values indicated a slight difference between the conceptual model and observed data. Furthermore, the RMSEA value (0.04) reflected high goodness of fit. The indices covariance values justified jointly by the model. The more GFI is closer to one the more appropriate the data fit. This index does not depend on sample size.

Table 3. Goodness of fit indices for store environment measurement model

\begin{tabular}{|c|c|c|c|c|c|c|c|}
\hline Factor & CMIN/df & P-value & RMR & RMSEA & AGFI & GFI & CFI \\
\hline Store environment & 0.985 & 0.12 & 0.04 & 0.04 & 0.91 & 0.93 & 0.92 \\
\hline
\end{tabular}

6.4. First-order confirmatory factor analysis for joy of shopping measurement model. The results in Figure 3 for joy of shopping measurement model suggested the factor loadings were adequate (greater than 0.5 ).

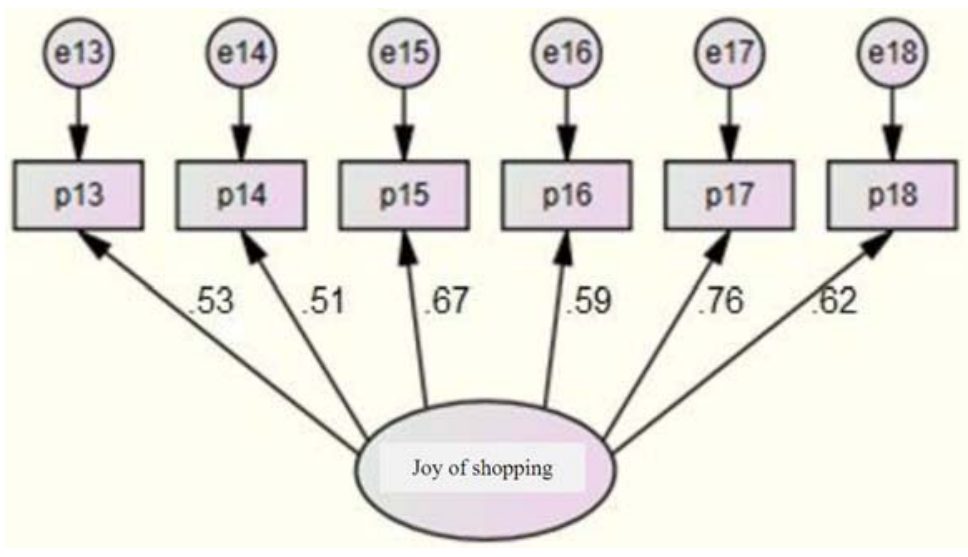

Fig. 3. First-order confirmatory factor analysis for joy of shopping 
According to figures displayed in Table 4, lower Chisquare values indicated a slight difference between the conceptual model and observed data. Furthermore, residual matrix is essentially used to assess the full and partial fits. The RMSEA value (0.04) reflected high goodness of fit and low model error.

Table 4. Goodness of fit indices for joy of shopping measurement model

\begin{tabular}{|c|c|c|c|c|c|c|c|}
\hline Factor & CMIN/df & P-value & RMR & RMSEA & AGFI & GFI & CFI \\
\hline Joy of shopping & 1.022 & 0.24 & 0.04 & 0.04 & 0.92 & 0.92 & 0.91 \\
\hline
\end{tabular}

6.5. First-order confirmatory factor analysis for brand loyalty measurement model. The results in Figure 4 for brand loyalty measurement model suggested the factor loadings were adequate (greater than 0.5 ).

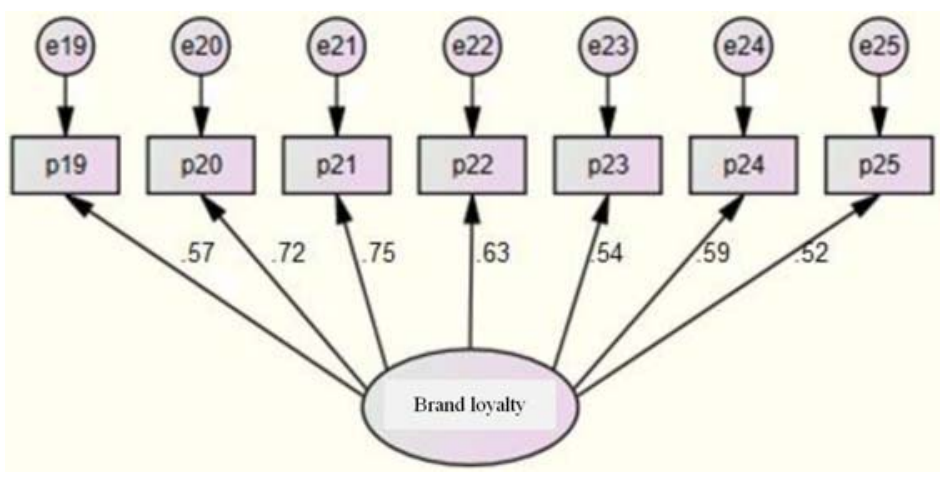

Fig. 4. First-order confirmatory factor analysis for brand loyalty

According to figures displayed in Table 5, lower Chisquare values indicated a slight difference between the conceptual model and observed data. One of the wellrecognized indices for evaluating goodness of fit is
GFI, which can be considered as a measure similar to $\mathrm{R}^{2}$ in multiple regressions. The more GFI is closer to one, the more adequate the data fit. Table 5 displays brand loyalty at desirable GFI value (0.91).

Table 5. Goodness of fit indices for brand loyalty measurement model

\begin{tabular}{|c|c|c|c|c|c|c|c|}
\hline Factor & CMIN/df & P-value & RMR & RMSEA & AGFI & GFI & CFI \\
\hline Brand loyalty & 1.167 & 0.32 & 0.05 & 0.04 & 0.91 & 0.91 & 0.90 \\
\hline
\end{tabular}

\section{Path analysis}

As one of the explanatory statistical measures, path analysis is based on regression relationships between variables so as to achieve the effect of each variable either direct or indirect. Path analysis involves a statistical technique adopting standard beta coefficient of multivariate regression in structural models. In fact, it serves to make quantitative estimates of causal relationships (unilateral interaction or covariance) between a set of variables. Construction of a causal model does not necessarily imply there are causal relationships between the model variables, but it is rather based on the correlational assumptions and research theoretical background. Path analysis indicates which path is more important or significant. The path coefficient is calculated based on the standardized regression coefficient. Figure 5 displays the path analysis for the conceptual model.

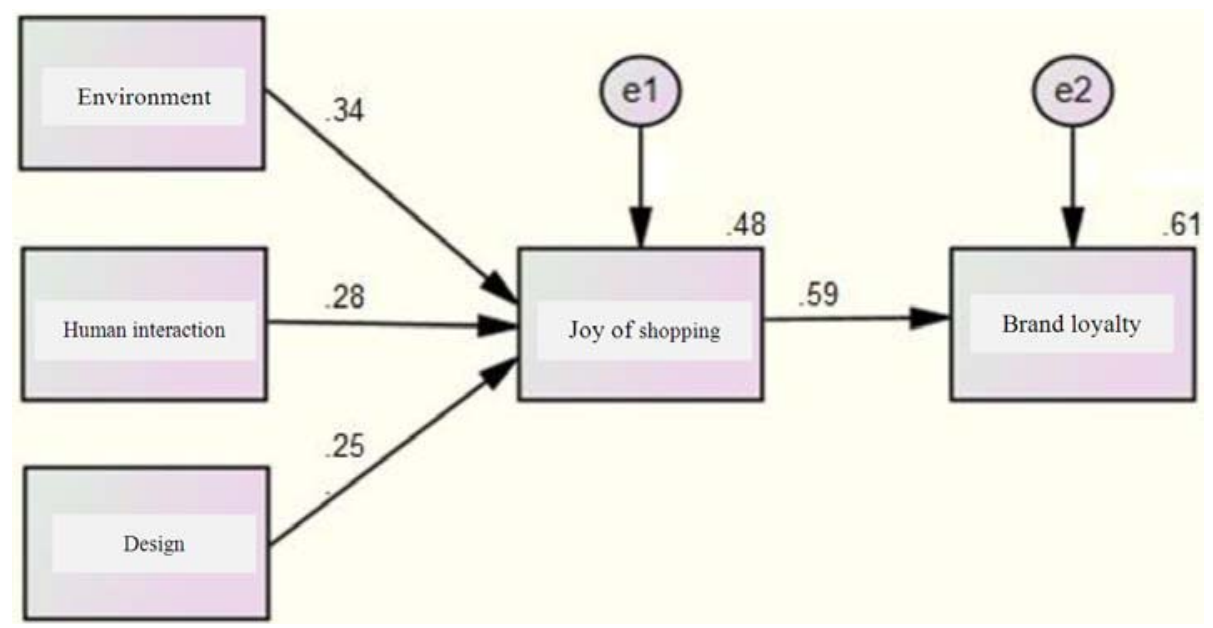

Fig. 5. Path analysis of conceptual model 
Given the figures displayed in Table 6, the model has adequate goodness of fit. Moreover, the indices of Chi-square $\left(X^{2}\right)$, GFI and AGFI are within the desirable range. The model has desirable goodness of fit, where $\mathrm{X}^{2} / \mathrm{df}$ is smaller than 3 and the values of GFI and AGFI are larger than 0.9 , while the RMR values are smaller than 0.4 .

Table 6. Goodness of fit indices for conceptual model

\begin{tabular}{|c|c|c|c|c|c|c|c|}
\hline Factor & CMIN/df & P-value & RMR & RMSEA & AGFI & GFI & CFI \\
\hline Conceptual model & 1.538 & 0.188 & 0.03 & 0.07 & 0.93 & 0.92 & 0.92 \\
\hline
\end{tabular}

Table 7. Direct standardized regression coefficients

\begin{tabular}{|l|c|c|c|c|}
\hline \multicolumn{1}{|c|}{ Direct effect } & Estimate & C.R. & P & Status \\
\hline Environment $\rightarrow$ Joy of shopping & 0.34 & 10.293 & 0.000 & Proved \\
\hline Human interaction $\rightarrow \rightarrow$ Joy of shopping & 0.28 & 7.439 & 0.000 & Proved \\
\hline Design $\rightarrow \rightarrow$ Joy of shopping & 0.25 & 6.617 & 0.000 & Proved \\
\hline Joy of shopping $\rightarrow$ Brand loyalty & 0.59 & 17.806 & 0.000 & Proved \\
\hline
\end{tabular}

According to the results displayed in Table 7, store environment affects joy of shopping (0.34) at a significance level smaller than 0.05 . Moreover, human interaction and design affect joy of shopping ( 0.28 and 0.25 , respectively) at a significance level smaller than 0.05 . Given the coefficient of determination $\left(\mathrm{R}^{2}\right)$ of 0.48 for joy of shopping, it can be argued that $48 \%$ of variations in joy of shopping can be explained by three variables of environment, human interaction and design.

According to the results extracted from Table 7, joy of shopping affects brand loyalty (0.59) at a significance level smaller than 0.05 . Given the coefficient of determination $\left(\mathrm{R}^{2}\right)$ of 0.61 for brand loyalty, it can be argued that $61 \%$ of variations in brand loyalty can be explained by joy of shopping.
Table 8. Indirect standardized regression coefficient

\begin{tabular}{|l|c|c|c|}
\hline \multicolumn{1}{|c|}{ Direct effect } & Estimate & $\mathrm{P}$ & Status \\
\hline Environment $\rightarrow$ Brand loyalty & 0.20 & 0.000 & Proved \\
\hline Human interaction $\rightarrow$ Brand loyalty & 0.16 & 0.000 & Proved \\
\hline Design $\rightarrow$ Brand loyalty & 0.14 & 0.000 & Proved \\
\hline
\end{tabular}

According to the results in Table 8 , store environment affects brand loyalty (0.20) indirectly through joy of shopping as an intermediating variable at a significance level of smaller than 0.05 . Moreover, human interaction and design affected brand loyalty $(0.16$ and 0.14$)$ indirectly at a significance level of smaller than 0.05 .

Generally, according to the results in Table 9, it can be concluded that store environment affected brand loyalty (0.20), while human interaction affected brand loyalty with total regression coefficient of 0.16 . Moreover, design affected brad loyalty with a total regression coefficient of 0.14 .

Table 9. Total standardized regression coefficients

\begin{tabular}{|l|l|c|c|c|}
\hline \multicolumn{1}{|c|}{ Hypothesis } & \multicolumn{1}{|c|}{ Total effect } & Indirect effect + direct effect $=$ Total effect & P & Status \\
\hline$H_{1}$ & Environment $\rightarrow$ Brand loyalty & $0.00+0.20=0.20$ & 0.000 & Proved \\
\hline$H_{2}$ & Human interaction $\rightarrow$ Brand loyalty & $0.00+0.16=0.16$ & 0.000 & Proved \\
\hline$H_{3}$ & Design $\rightarrow$ Brand loyalty & $0.00+0.14=0.14$ & 0.000 & Proved \\
\hline$H_{4}$ & Joy of shopping $\rightarrow$ Brand loyalty & 0.59 & 0.000 & Proved \\
\hline
\end{tabular}

\section{Discussion and conclusions}

One of the undeniable facts of business and competitive world today is the impact of store interior design on behavior and purchase rate of customers. Various store-owners tend to provide an ideal business environment for their customers. The findings of this research suggested there is a significant effect of store environment on loyalty and joy of shopping. These findings were compared against those of previous relevant studies:

Hio Jong Chang et al. (2011) believed that in-store environmental characteristics are effective in positive emotional response of consumers. Tendai and Krispen (2009) believed that in-store environment affects impulse purchase, considering coupons, in-store displays, advertising, employee behavior and prices as the most important factors on customer purchase behavior. Zhou and Wong (2008) believed that in-store stimuli affected customers' purchasing behavior involving in-store posters as environmental stimuli. In a study on impulse purchase, personality traits, in-store atmosphere and their relationship, Nakheel Jalan (2005) divided the factors contributing to impulse purchase into internal and external factors.

The former was characterized by subcategories of sensation and personality characteristics, while the latter involved demographic, social, economic, 
marketers, etc. The internal factors involved environment, design, society, etc. It was concluded that in-store factors affected impulse purchase as much as external factors. Hosseini et al. (2013) studied the effect of music clips on in-store purchase rate (duration of customer stay), arguing that the issue of competition in today's world is no longer limited to manufacturing enterprises, but rather covers the suppliers particularly large retail sellers.

Due to the Iranian cultural infrastructure, these large retail sellers have to face a huge crowd of small retailers who need to attract more customers and enhance purchase rate through employment of modern marketing techniques so as to expand the duration of customer stay inside the store and subsequently increase the chances of purchase. The results of that study obtained through path analysis indicated that music clips affected customer purchase rate by extending the in-store duration. Generally, according to the previous studies and the results of the current study, it can be stated that store environment and its elements have a significant impact on customer loyalty to the store and repeat purchases.

\section{References}

1. Amirshahi, M., Kazemein, M., Yavari, N. (2009). Identifying and ranking the factors contributing to customer loyalty, Journal of modern marketing research, 3, pp. 152-171.

2. Rafee, S., Haghighinasab, M. and Yazdani, H. (2012). The effect of marketing mixed factors and company image on special brand value at Software Sector of IT industry, Journal of modern marketing research, 4, pp. 182-195.

3. Samadi, M., Hasanizadeh, A., Nourani, K.M. (2010). A study on the relationship between marketing tactics of communicational marketing for chain stores and consumer purchase behavior, Business Administration, 24, pp. 11-93.

4. Simon, J. and Minor, M.S. (2007). Consumer behavior, translated by Abbas Saleh Ardestani and Mohammadreza Saadi. Tehran: Etehad Publications. 